\title{
Modified Symbiotic Organisms Search for Plug-In Hybrid Electric Vehicles through Renewable Micro-Grids
}

\author{
Dr. P. Karrupusamy, Professor, \\ Department of Electronic and Communication Engineering, \\ Shree Venkateshwara Hi-Tech Engineering College, India. \\ Email id: pkarrupusamyphd@gmail.com
}

\begin{abstract}
This paper uses a modern stochastic framework for studying the storage devices, PHEVs (plug-in hybrid electric vehicles), RESs (renewable energy sources) and such MGs (micro grids) for optimal management of energy while applying the popular Monte Carlo simulation technique for modelling the uncertainties of RESs and PHEVs. Prominent charging patterns namely uncontrolled, smart and controlled charging schemes are implemented for analysis of response in MGs for varied PHEV charging behaviours. Simultaneously, we also apply a powerful and robust Symbiotic Organisms Search (SOS) algorithm for analysing the uncertain parameter behaviours in natural stochastic form and the optimal MG operation. The interactions observed in natural organisms that depend on other organisms for survival are simulated by SOS. The total search ability in global and local searches is improved effectively using the modified SOS algorithm. Multiple MG test systems with varied scheduling time limits are used for examination of the proposed technique and its performance. In the presence as well as absence of PHEV charging effects, comparison of proposed technique and other algorithms are conducted with case studies under diverse conditions.
\end{abstract}

Keywords: Uncertainty; Renewable micro-grid; Plug-in hybrid electric vehicles (PHEVs); Storage device; Symbiotic organism search (SOS);

\section{Introduction}

At the distribution level of power systems, improved energy efficiency, reliable services, higher power quality and avoiding environmental concerns are the factors that contribute towards the socioeconomic growth in the recent days. Alternative sources of renewable energy such as WTs (wind turbines) and PVs (photovoltaics) are used as a response for the above mentioned issues [1]. MTs (micro turbines), FCs (fuel cells) and such DGs (distributed generations) offer new arenas for more efficiency active power systems in the near future [2]. For secure, successful and efficient distribution of electricity, favourable targets can be attained using the various alternative sources offered by the MG. Heat and power can be offered locally by means of MG concepts that use micro-sources and load clusters that operate as a single controllable module [3]. New smart grids with DGs can be applied for the generation of benefits and challenges that are managed by the idea of MG. There is a rapid increase in the literature on the investigation of MG in the recent years.

For minimising the expenses during the lifetime of MG, in the perspectives of operation, design and planning, the renewable MG is investigated [4]. The combination of a battery system and PV system in the MG for a flexible operation and agent-based technique application are also studied by various 
researchers. Application of right timing and implementation of mix-integer linear programming for optimising the supply performance in renewable MG is done by means of optimal operation technique in certain research implementations [5]. Further, the implementation of a smart deterministic minimisation method is investigated over a period of seven days for a renewable MG laboratory using optimal management of energy. Various market policies and optimization of exchanged power as well as local production is analysed for interconnected operational mode in MG [6]. The real-coded genetic algorithm is applied for optimization, storage and forecast planning for minimisation of the cost of MG. Depending on the storage battery and WT, the day-ahead unit commitment participation for contribution policy is also proposed for optimization [7].

\section{Related Works}

Electricity consuming Electric Vehicles (EVs) and the fossil energy as well as electricity based plug-in hybrid electric vehicles (PHEVs) are both referred as plug-in electric vehicles (PEVs) that may use an external electricity network for the purpose of recharging [8]. Reduction of emission of green house gases is gaining attention due to the upsurge in the price of petroleum [9]. The quantity of batteries that are being charges, capacity of the battery, time duration of charging, commencement of charging, State of Charge (SOC) of the battery, charging technique and charger type are some of the factors that influence the performance of charging in PHEVs [10]. The charging factors involved and their uncertain behaviour leads to irresolution in the sum of vehicles load in case of a MG based PHEVs charging demand [11]. This study analyses the smart, uncontrolled and controlled schemes of charging to study the MG based PHEV charging effects [12].

Charging a vehicle by plugging it every evening on arrival of the vehicle to home is the easiest strategy of charging among all the available schemes of charging [13]. This is because most of the EVs, both company-owned and privately owned are operational during the morning and the recharge cycle is to be chosen based on the usage of the vehicle, either on every alternate day or everyday excluding weekends [14]. Majority of the EVs charging demands are satisfied by these models. In case of an uncontrolled method of charging an EV, the average charging time is analysed using the grid loading data. In between 6 to 7 PM, a rectangular probability density function (PDF) is used for modelling the inaccuracy and uncertainty of the scenario [15]. Based on the PDF, determination of specific levels of probability is done within the given time while the PHEVs are being charged. Modelling of uncertainty is performed using Monte Carlo simulation (MCS) technique. The probability functions of other statistical data can also be considered similarly [16].

\section{Proposed Work}

This metaheuristic algorithm termed as SOS was developed by Cheng and Prayog based on the symbiotic relationship used by organisms including plants and animals for interaction and survival in the ecosystem. In a specific search space, the randomly formed species are grouped together which 
Journal of Electrical Engineering and Automation (EEA) (2020)

Vol.02/ No. 02

Pages: $76-83$

https://www.irojournals.com/iroeea

DOI: https://doi.org/10.36548/jeea.2020.2.003

forms an ecosystem where commencement of SOS occurs. Figure 1 describes the SOS algorithm in a flow chart format with the MG operation management and PHEV charging. The mathematical models that are described in the subsequent equations that are the components of the three major stages of interaction of organisms involved in this algorithm.

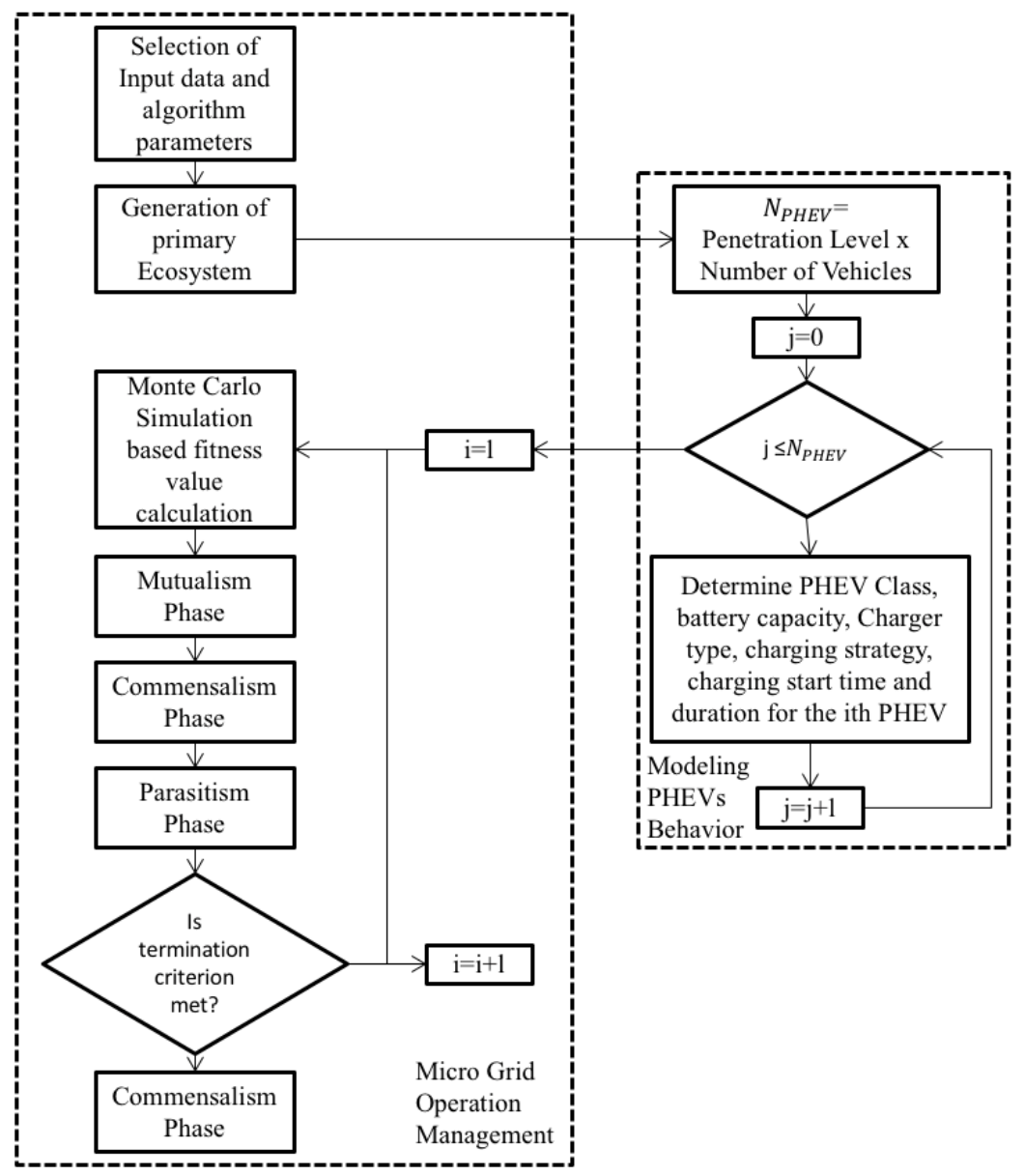

Figure 1: Flowchart of PHEV charging based MG operation management

The relationship among two diverse species of organisms in symbiotic terms that seek advantage mutually is termed as mutualism. $\mathrm{O}_{i}$ and $\mathrm{O}_{j}$ is the mutual interaction between $\mathrm{O}_{\text {inew }}$ and $\mathrm{O}_{\text {jnew }}$ modified organisms that is modelled by the equations 1 and 2 given below. New and modified organisms replace the organisms $\mathrm{O}_{\mathrm{i}}$ and $\mathrm{O}_{\mathrm{j}}$ if they are fitter than the existing ones.

$$
\begin{gathered}
O_{\text {inew }}=O_{i}+\operatorname{rand}(0,1) \times\left(O_{\text {best }}-M V \times B F_{1}\right)------(1) \\
O_{\text {jnew }}=O_{j}+\operatorname{rand}(0,1) \times\left(O_{\text {best }}-M V \times B F_{2}\right)------(2)
\end{gathered}
$$




$$
M V=\left(\frac{O_{i}+O_{j}}{2}\right)
$$

Interaction among two diverse organisms wherein without harming the other organism, one organism seeks advantage - this phenomenon is termed as commensalism. Equation 4 represents a relationship in which advantage from $\mathrm{O}_{\mathrm{j}}$ is obtained by organism $\mathrm{O}_{\mathrm{i}}$ without harming the other organism.

$$
O_{\text {inew }}=O_{i}+\operatorname{rand}(-1,1) \times\left(O_{\text {best }}-O_{j}\right)------(4)
$$

Interaction among two diverse organisms is considered as parasitism, however, unlike commensalism, in this technique, the interaction may profit one species while it hurts the other. In certain cases, the other organism can even be killed by the parasites and randomly replaced by another organism by the host. The implementation of the algorithm involves various steps such as collection of input data, PHEV hourly charge calculation, initial population generation, objective function calculation, selection of the best solution, improving and updating the population based on mutualism phase, commensalism phase and parasitism phase, using the proposed modification technique for improving the SOS population, based on the new improved population updating the best solution position and continuing the process until the satisfaction of termination criterion.

\section{Results and Discussion}

Figure 2 represents the first test system and its single-diagram. In order to analyse the behaviour of MG and PHEVs, the MSOS algorithm is implemented and its performance is tested using case studies under two scenarios. The status of DG and initial charging status of the battery are also considered for this purpose. Along with this, certain well-known algorithms are considered for comparison with the performance of MSOS algorithm disregarding the issues and uncertainties of the scenario by applying them on MG without PHEVs. A study period of 24 hours in which all DGs are active with an indefinitely charged battery is used in the first scenario. Starting up or shutting down of the DG is possible during the second scenario study period where the battery is not charged initially. The available outputs of WT and PV are exploited fully in both the scenarios. After the first capital investment, these devices should generate an encouraging and forcing policy that supports PV and WT. 
Journal of Electrical Engineering and Automation (EEA) (2020)

Vol.02/ No. 02

Pages: 76- 83

https://www.irojournals.com/iroeea

DOI: https://doi.org/10.36548/jeea.2020.2.003

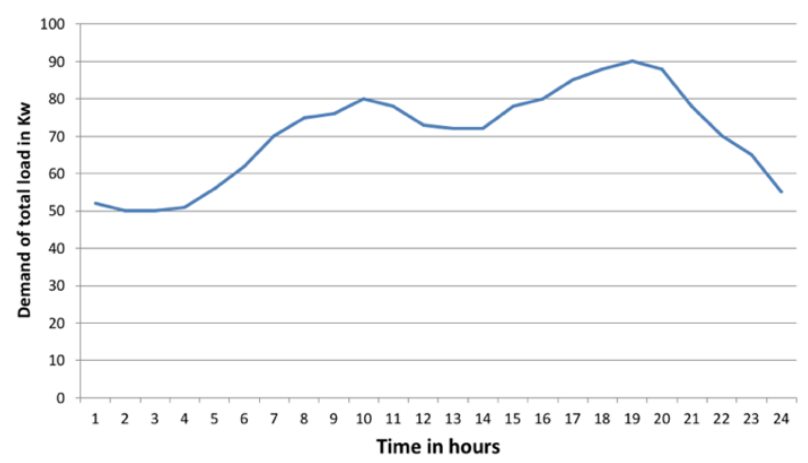

Figure 2: Typical MG load demand estimation

Figure 2 represents the hourly load demand estimated and the parameters of the algorithm that represents the issues with respect to the limits and bids of DGs. The output power of WT and PV are forecasted on an hourly basis for over a 24-hour simulation duration in the first test system. Comparison of the available systems in the domain and the proposed system in terms of performance and efficiency is better calculated when the scheduling is done over a duration of 24 hours. However, extension of the duration over weeks, moths or years can also be done for practical analysis. Extension of the analysis time window does not impose any change or limitation in the solution for the underlying problem.

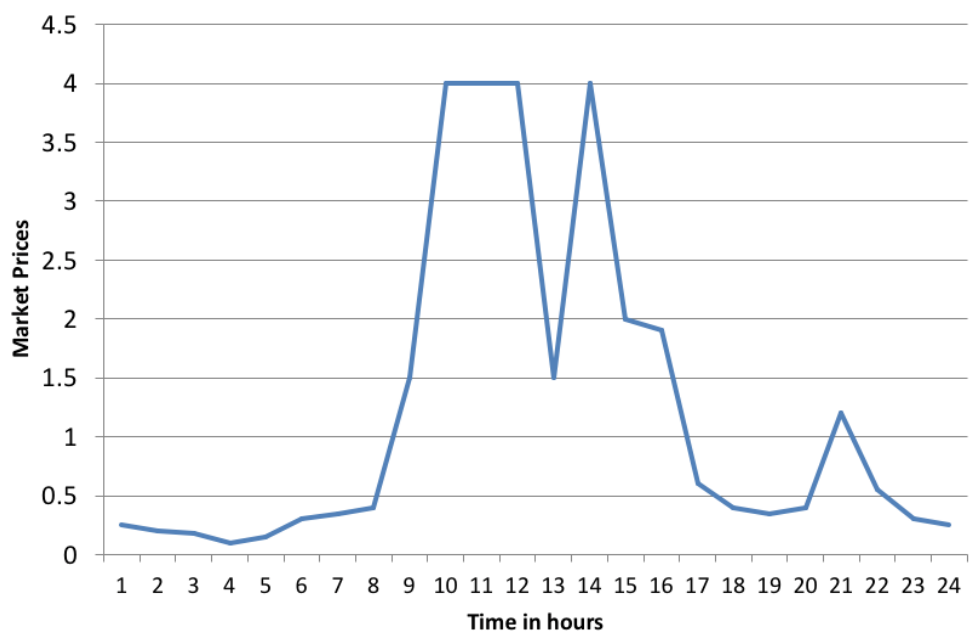

Figure 3: Hourly utility market 
Journal of Electrical Engineering and Automation (EEA) (2020)

Vol.02/ No. 02

Pages: $76-83$

https://www.irojournals.com/iroeea

DOI: https://doi.org/10.36548/jeea.2020.2.003

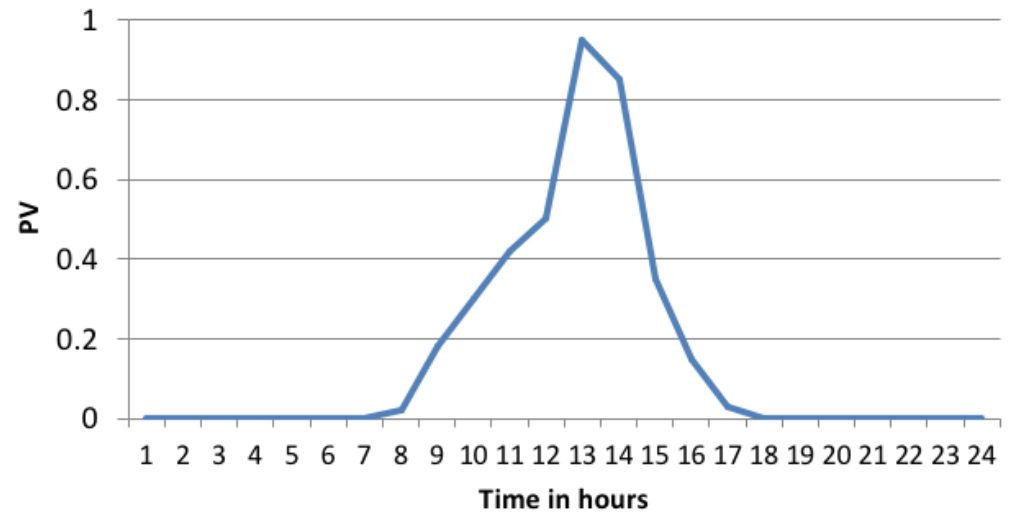

Figure 4: Normalised PV output power estimation

Figure 3 and 4 provides the hourly utility market and the normalised PV output power estimation of the 24-hour estimation scenario. For this purpose, we use a test system with the components involved - a load, NiMH battery, various DGs, three feeders, the main grid and a $400 \mathrm{~V}$ MG. The parameters of the algorithm, problem values, estimated load demand on hourly basis, outputs of WT and PV forecasted on hourly basis, limits and bids of DG and the utility market price on hourly basis are simulated over a duration of 24 hours in the first test system. In the second step, the current best solution is chosen and the average value of population is moved towards it. In this scenario, charging of the battery is to be done in in initial hours as it is considered to be flat at the beginning and will be discharged later. In comparison with the prominent algorithms available, the MSOS offers better performance. Out of around 70 PHEV vehicles considered, the penetration level is around $30 \%$ in the MGs.

Table 1:MG test system and cost function comparison

\begin{tabular}{|lccccc|}
\hline Method & $\begin{array}{c}\text { Mean simulation } \\
\text { time in seconds }\end{array}$ & $\begin{array}{c}\text { Standard } \\
\text { deviation }\end{array}$ & Average & Best Solution & $\begin{array}{c}\text { Worst } \\
\text { Solution }\end{array}$ \\
\hline MSOS & 7.664 & 0.0000 & 264.7601 & 267.7601 & 264.7601 \\
\hline SOS & 9.501 & 0.9735 & 268.6542 & 267.8744 & 269.6700 \\
\hline AMPSO-L & - & 0.0922 & 274.5644 & 274.4318 & 274.4318 \\
\hline AMPSO-T & - & 0.3211 & 274.9822 & 274.5508 & 274.5508 \\
\hline CPSO-L & - & 5.9698 & 276.3327 & 274.7439 & 274.7439 \\
\hline CPSO-T & - & 6.2342 & 277.4046 & 275.0456 & 275.0456 \\
\hline FSAPSO & - & 8.3302 & 280.6844 & 276.7868 & 276.7868 \\
\hline PSO & - & 10.1822 & 288.8762 & 277.3238 & 277.3238 \\
\hline GA & - & 13.4422 & 290.4322 & 277.7445 & 277.7445 \\
\hline
\end{tabular}

Table 1 shows the results of simulation of the second scenario where battery charging is performed during the initial hours as it is flat at the beginning. The most expensive DG in this scenario is MT. 
Journal of Electrical Engineering and Automation (EEA) (2020)

Vol.02/ No. 02

Pages: 76- 83

https://www.irojournals.com/iroeea

DOI: https://doi.org/10.36548/jeea.2020.2.003

During peak-load hours, the stored energy is sold to the main grid thereby reducing the overall cost of the MG. The maximum power capacity is used for production of energy during the initial hours of the day by the FC and utility while the later hours of the day exhibits high costs for charging. This makes it an economically poor power unit while it can be compensated by energy sharing in the later stages. Also, for reduction of total costs, the MGCC can be shut down for a few hours when the vehicle is non operational.

\section{Conclusion}

MT, PV, FC and WT are some of the types of renewable sources of energy that are incorporated in the typical MG for optimal management of operation in which the charging demands of PHEV and its effects are investigated in this paper. The cost of MG is affected by the storage by the battery in a positive manner. Smart, controlled and uncontrolled charging techniques are the major strategies of charging that are considered for analysis in this paper. Two test systems are simulated and analysed and it is concluded that the proposed MSOS algorithm offers improved performance when compared to several other prominent algorithms in this domain. The total cost and effect of MG can be reduced efficiently by using a smart charging strategy compared to the traditional implementations where the total cost of MG is increased due to the charging demands of PHEV. When compared to the controlled or uncontrolled charging schemes, the cost reduction is more efficient in the implementation of smart charging pattern. The proposed MG management framework offers satisfying and reliable performance. Further optimization of the framework and improving the efficiency is of future scope.

\section{References}

[1] Moghaddas-Tafreshi, S. M., Jafari, M., Mohseni, S., \& Kelly, S. (2019). Optimal operation of an energy hub considering the uncertainty associated with the power consumption of plug-in hybrid electric vehicles using information gap decision theory. International Journal of Electrical Power \& Energy Systems, 112, 92-108.

[2] Kheradmand-Khanekehdani, H., \& Gitizadeh, M. (2018). Well-being analysis of distribution network in the presence of electric vehicles. Energy, 155, 610-619.

[3] Vincent, F. Y., Redi, A. P., Yang, C. L., Ruskartina, E., \& Santosa, B. (2017). Symbiotic organisms search and two solution representations for solving the capacitated vehicle routing problem. Applied Soft Computing, 52, 657-672.

[4] Cheng, M. Y., \& Prayogo, D. (2016). Modeling the permanent deformation behavior of asphalt mixtures using a novel hybrid computational intelligence (Doctoral dissertation, International Association for Automation and Robotics in Construction (IAARC)).

[5] Truong, K. H., Nallagownden, P., Baharudin, Z., \& Vo, D. N. (2019). A quasi-oppositionalchaotic symbiotic organisms search algorithm for global optimization problems. Applied Soft Computing, 77, 567-583.

[6] Gharehchopogh, F. S., Shayanfar, H., \& Gholizadeh, H. (2019). A comprehensive survey on symbiotic organisms search algorithms. Artificial Intelligence Review, 1-48. 
Journal of Electrical Engineering and Automation (EEA) (2020)

Vol.02/ No. 02

Pages: 76- 83

https://www.irojournals.com/iroeea

DOI: https://doi.org/10.36548/jeea.2020.2.003

[7] Sarshar, J., Moosapour, S. S., \& Joorabian, M. (2017). Multi-objective energy management of a micro-grid considering uncertainty in wind power forecasting. Energy, 139, 680-693.

[8] Farnad, B., Jafarian, A., \& Baleanu, D. (2018). A new hybrid algorithm for continuous optimization problem. Applied Mathematical Modelling, 55, 652-673.

[9] Aluisio, B., Bruno, S., De Bellis, L., Dicorato, M., Forte, G., \& Trovato, M. (2019). DCmicrogrid operation planning for an electric vehicle supply infrastructure. Applied Sciences, 9(13), 2687.

[10] Barhagh, S. S., Mohammadi-Ivatloo, B., Anvari-Moghaddam, A., \& Asadi, S. (2019). Risk-involved participation of electric vehicle aggregator in energy markets with robust decision-making approach. Journal of Cleaner Production, 239, 118076.

[11] Nikmehr, N., Najafi-Ravadanegh, S., \& Khodaei, A. (2017). Probabilistic optimal scheduling of networked microgrids considering time-based demand response programs under uncertainty. Applied energy, 198, 267-279.

[12] Latif, A., Hussain, S. S., Das, D. C., \& Ustun, T. S. (2020). State-of-the-art of controllers and soft computing techniques for regulated load frequency management of single/multiarea traditional and renewable energy based power systems. Applied Energy, 266, 114858.

[13] Mostafa, M. H., Aleem, S. H. A., Ali, S. G., Abdelaziz, A. Y., Ribeiro, P. F., \& Ali, Z. M. (2020). Robust Energy Management and Economic Analysis of Microgrids Considering Different Battery Characteristics. IEEE Access, 8, 54751-54775.

[14] Chauhan, R. K., \& Chauhan, K. (Eds.). (2019). Distributed Energy Resources in Microgrids: Integration, Challenges and Optimization. Academic Press.

[15] Mostafa, M. H., Ali, S. G., Aleem, S. H. E. A., \& Abdelaziz, A. Y. (2018, December). Optimal Allocation of Energy Storage System for Improving Performance of Microgrid Using Symbiotic Organisms Search. In 2018 Twentieth International Middle East Power Systems Conference (MEPCON) (pp. 474-479). IEEE.

[16] Dey, B., Roy, S. K., \& Bhattacharyya, B. (2019). Solving multi-objective economic emission dispatch of a renewable integrated microgrid using latest bio-inspired algorithms. Engineering Science and Technology, an International Journal, 22(1), 55-66.

\section{Biography}

Dr. P. Karrupusamy working as a Professor and Head in Department of Electrical and Electronics Engineering at Shree Venkateshwara Hi-Tech Engineering College, Erode. In 2017, He had completed doctorate in Anna University, Chennai and in 2007, he had completed his post graduate Power Electronics and Drives in Government College of Technology, Coimbatore, India. He has more than 10 years of teaching experience. He has published more than 40 papers in national and international journals and conferences. He has acted as conference chair in IEEE international conferences and Guest editor in reputed journals. His research area includes Modeling of PV arrays, Adaptive Neuro-Fuzzy Model for Grid Connected Photovoltaic System with Multilevel Inverter. 